\title{
Factual Video Advertisements in Facebook
}

\section{S. Habeeb Ur Rahaman}

\begin{abstract}
Advertising is the basic requirement of promotion. It is used in all sectors of business to promote their company or product. There are many different ways of advertisement that are used according to the requirement of the product. Social media is one of the most accessible media in today's scenario. Advertising through News paper, Television, Radio still exists but the internet usage and social media accessibility has made the advertisers to find new ways of advertising such as social media advertisement. Social media such as Facebook plays a vital role in advertisements. Advertisements can be of images, graphics and animation but the new way of advertising is through factual videos. These factual videos advertisements will give the real videos of how a work is done by an employer or the machine which he uses. The factual videos will create a trust on the company and their works which they show through the video. Facebook allows the companies to create a page for promotion of their products. This research is to find out how far this factual video advertisement is helpful in promoting the company. Five different factual video advertisements are selected and analysed based on their comments, likes and shares. Content analysis method is used for analysing the likes, shares, comments. Anurag makeup mantra, Zayaans Exclusive Collection, Z.M Online, Fashion Fever,GoBumpr, Women Fashions these are the five factual video advertisements selected from Facebook.
\end{abstract}

Keywords : Social Media, Advertisements, Facebook.

\section{INTRODUCTION}

Social media marketing is the new way of online advertisement that done with the help of social networking websites. The main aim of this advertising method is to produce content that can be response by the viewer and give their valuable comments and they can also share the advertisement to their friends. With this idea the advertisement is promoted to a large number of people without any cost. Social media advertising is most cost effective and time consuming advertisement method. The company which start their promotion through their website also like Facebook to website so that the viewer who likes to go through the Facebook can go to Facebook and view the pictures, videos and content. As like web page there is a page in Facebook which was created by the every organization so that page will have the entire posted picture, videos and other content of the company. When an organization start a page in Facebook while registering the page the Facebook will ask for the privacy for whom this ads has to be shown in that case the company can select their preferred audience group by

Revised Manuscript Received on December 05, 2019.

* Correspondence Author

S. Habeeb Ur Rahaman*, Assistant Professor, School of Media Studies, Patrician College of Arts \& Science, Adyar, Chennai, India.

selecting the age group. So through this method the company can easily locate their audience. Whenever the company is posting a video regarding the product or working progress the company can post it for all users to view. Thisadvertising method is used by many companies in promoting themselves using face book. The advertisement is also providing the viewers to like, share and comment on the video post

\section{LITERATURE REVIEW}

According to N. Giri and S. Benjamin Christopher (2015), Facebook help the students to their valuable suggestions on the product that they purchased and they also post the photos and video description of the product which will help others to decide on purchase of same product.

According to James Barnes (2014) business owners should implement the organic engagement for promotion so that the fans for the particular product will share the advertisement and recommend it to their friends.

According to Jurgita Raudeliunien (2018) conducting an advertisement campaign on social network is helpful for the organization to identify the relationship between the company and the costumer. It will also help to invest on building relationship with the costumers in future.

According to Kevin Curran, the people who are doing business can easily identify their target audience whom they want to see their ads or Facebook page. These targeting features will help the business people to spent money only on the selected audience instead of the current users.

According to MiladDehghani and Mustafa Tumer (2015) the social media users who are willing to purchase a product is based on the number of "like's" and "share's" that product has received from the other users. So using these aspects they intent to believe themselves that the product is reputed.

According to Mohammad Mazibar Rahman \& Md. Mamunar Rashid (2018),companies which are seeking for promotion of their products through social media should encourage and attract the users who have a good approach towards social media advertisements.

According to Shariful Islam and Mohammad Iqbal Mahmood (2018), there is a source of attraction towards the social media advertisements among the social media users. So through this social media advertisements the viewers will decide on purchasing of a product.

\section{METHODOLOGY}

Content analysis is a research technique used to analyse or evaluate the selected documents, images, videos related to 


\section{Factual Video Advertisements in Facebook}

the research. In this research five different Facebook factual video advertisements are taken as sample. Attributes like number of like's, share's, comment's, view's that is being received by each advertisement.

Though this attributes we can know how far the factual video advertisement is useful in promotion of products, companies, services.

\section{ANALYSIS OF ADVERTISEMENTS}

Social media advertisements are getting more popular in today's world. New innovate ideas of advertisements are mostly seen through internet. Factual video advertisements is started based on the time line videos posting in face book. While a video is posted in time line by a user the video is available for all the users to see in that most of them will comment, like and share the video in their time line. Factual videos are used in advertisement today by many of the companies. These companies use such video to state that the actual product or service will reside the same as shown in the video. Comparing with the animated videos or graphics, factual videos will be more interesting to watch and it will give a clear idea about what is the actual product or service.

Table-1

\begin{tabular}{|l|l|l|l|l|l|}
\hline \multirow{2}{*}{ Parameters } & \multicolumn{5}{|l}{ Name of the company/ organization/ service } \\
\cline { 2 - 6 } & $\begin{array}{l}\text { Anurag } \\
\text { makeup } \\
\text { mantra }\end{array}$ & $\begin{array}{l}\text { Zayaans } \\
\text { Exclusive } \\
\text { Collection }\end{array}$ & $\begin{array}{l}\text { Z.M } \\
\text { Online } \\
\text { Fashion } \\
\text { Fever }\end{array}$ & GoBumpr & $\begin{array}{l}\text { Women } \\
\text { Fashions }\end{array}$ \\
\hline View's & $\begin{array}{l}1.5 \\
\text { Million }\end{array}$ & 32000 & 17000 & 44000 & 62000 \\
\hline Like's & 90,000 & 693 & 26 & 170 & 131 \\
\hline Share's & 4512 & 2252 & 43 & 28 & 87 \\
\hline Comment's & 2300 & 1175 & 133 & 27 & 5 \\
\hline
\end{tabular}

Factual video advertisement is mostly seen in women fashion, accessories, automobiles and other commercial products. According to the table there are five different factual video advertisement that gives detail on different parameters. Based on these parameters we can know how far these advertisements are promoted and how people invite see such advertisements.

Anurag makeup mantra(lab) studio is the first listed company in the table which is located in Mumbai and it deals with makeup for bridal women and Men. It works as an institute to train on makeup techniques. This company has posted a factual video of doing makeup for a women where they prepare her for marriage. Through this video they want to promote themselves about their work and want people to joint in their training institute. So factual video is helpful for the viewers to know about the company around 1.5 Million have viewed this advertisement and about 4512 people shared this video to their timeline this show the interest of the people in watching the factual video advertisement.

Zayaans Exclusive Collection is the second listed company which is handled by an individual lady who is selling clothes for women. When a women goes to a shop for purchase of cloths the clothes will be opened from the pack and the design of the cloth will be shown to them clearly. In that case the factual video advertisement which was posted by this company has a clear explanation about the clothes. The lady herself acted in the video for explain the product which has gained 32,000 views. The video is also shared to 2252 people which means a woman who has watched this video has recommended for her friends. thus the other parameters such as like's, comments were also good for this factual video advertisement.

Z.M Online Fashion Fever is the foot wear selling online shop which has posted a factual video of new foot wear arrivals. Usually the footwear which we see in the online is always a designed one. Which purchasing footwear from a website you can the 3D design products but here they have made a simple video which will speak about the real product. Thus by seeing the video the people can identify the quality of the product and they will show interest in buying the product. This video has got 17000 views which states that many of them have watch and show their interest towards the product. GoBumpris the automobile servicing company which deals with two wheeler and four wheeler service. The company provides the door step service for both vehicles. To make the people to believe that their service is genuine and in what method they do service they use factual video advertisement. They have posted many different videos of services that they do for cars and bikes. Here this data given in table 1 is about a dent repair video of a car. The data states that 44,000 have viewed the advertisement. So thus this factual video advertisement will help the people who won car with dent to think on whether to opt this service or not.

\section{Figure 1 \& 2: Examples of Factual Video Advertisements}
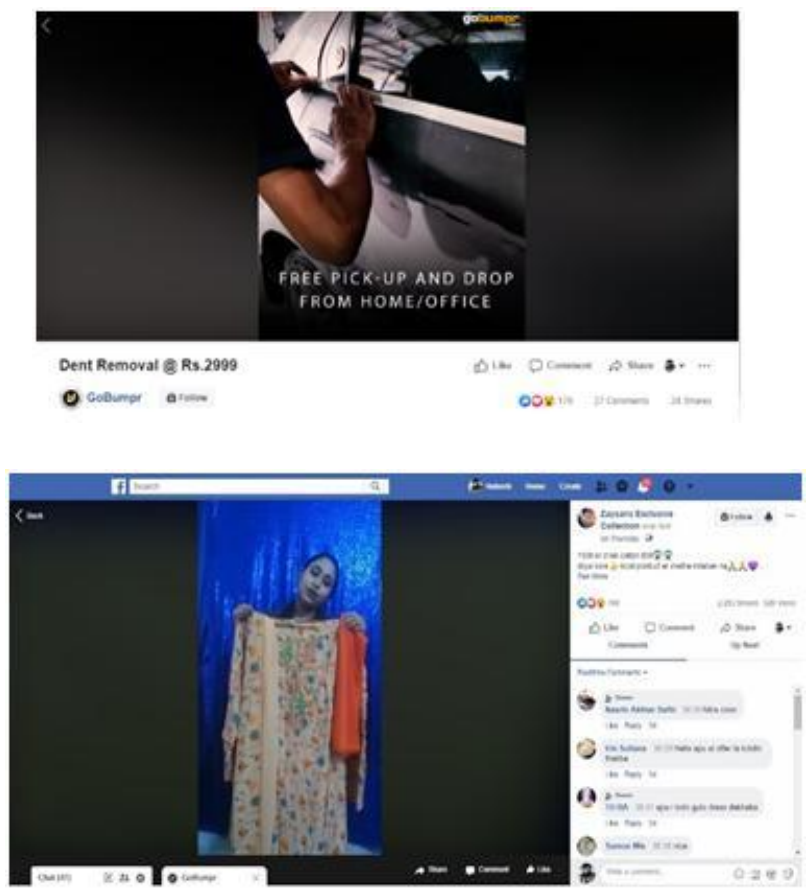

Published By:

Blue Eyes Intelligence Engineering \& Sciences Publication 
Women Fashions is online media company which is listed last in the table-1 show above. This company gives information all about fashions through online media. They post videos that are useful for young women who looks for new fashion and makeup. This company has given a practical tutorial of how to get make your makeup by yourself for women.

This tutorial is an factual video where a makeup artist sit in front of the camera and uses all sorts of cosmetics thus this factual video tutorial become the advertisement for the company where more subscribers will join in the group to watch these videos. This factual video has been seen by 62000 viewers.

\section{CONCLUSIONS}

Advertisement is the larger part of online business which is carried out through many different forms like website, blog, social media. Facebook is advertisement is more useful since many of them access to social media. The main motto of advertisement is to attract the viewers. Factual videos are more attractive in the form of advertisement. The latest generation is expecting everything to be in the form of video for better understanding in that case if the videos are real it is much better for them to understand about the organization or the products. Thus through this analysis of advertisement we can conclude that people expect factual videos in advertisement for easy understanding. Further research can be done on the comparison of the video quality and presentation of video.

\section{REFERENCES}

1. N. Giri and S. Benjamin Christopher,(2015) Impact of Facebook on the Buying Behaviour of Students

2. James BarnesSocial Advertising Using Facebook: Some Experimental Results Using Duck Dynasty Ads to Promote Rural Tourism in Mississippi (2013)

3. JurgitaRaudeliunienEvaluation of Advertising Campaigns on SocialMedia Networks(2018) Kevin Curran, Advertising on Facebook(2011)

4. MiladDehghani and Mustafa TumerA research on effectiveness of Facebook advertising on enhancingpurchase intention of consumers(2015)

5. Mohammad Mazibar Rahman \& Md. Mamunar Rashid, Social Media Advertising Response and its Effectiveness: Case of South Asian (2018)Teenage Customers

6. Shariful Islam and Mohammad Iqbal Mahmood, A Qualitative Study on the Outcomesof Social Media Advertising (2018)

Advertisement Links

7. https://www.facebook.com/381135312234610/videos/21139323786916 24/

8. https://www.facebook.com/555018821340420/videos/35879052173586 $7 /$

9. https://www.facebook.com/z.monline.trading/videos/519248872162843/

10. https://www.facebook.com/letsgobumpr/videos/462741127890568/

11. https://www.facebook.com/Fashionshala.official/videos/2208328489428 952/

\section{AUTHOR PROFILE}

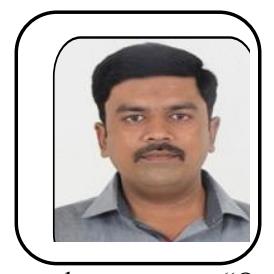

S Habeeb Ur Rahaman, Working as an Assistant Professor in Patrician College of Arts and Science, 2013 - till date. Pursuing Ph.D from Sathyabama University, Holds MSc. Electronic Media St.Thomas College of Arts and Science - 2012, Holds BSc.Visual Communication - The New College 2010. Completed 8 week course on "Introduction to Research" during Aug- Sep 2018. Completed 12 week course on "Qualitative research Methods" during Jan- Apr 2019.
Completed 12 week course on "Introduction to Film studies" during Jul- Dec 2019. 